\title{
LA INSCRIPCIÓN CONSTITUTIVA DE LA HIPOTECA. SU IMPORTANCIA PARA LA EJECUCIÓN
}

\author{
OLGA FUENTES SORIANO \\ Prof ${ }^{a}$ Titular Interina Univ. \\ Área de Derecho Procesal.
}

\section{INTRODUCCIÓN}

Uno de los temas que, sin duda, causó importantes polémicas desde el momento de su introducción en nuestro sistema jurídico fue el de la inscripción con carácter constitutivo del derecho real de hipoteca. Como es de todos sabido, la inscripción registral de los derechos reales tiene en nuestro Ordenamiento Jurídico, como norma general, carácter declarativo (art. 606 C.C). Para la hipoteca, sin embargo, tanto el art. 1.875 C.C. cuanto los arts. 145 y 159 L.H. trataron de inaugurar en nuestro sistema jurídico el carácter constitutivo de su acceso al Registro de la Propiedad.

La importancia de estudiar este tema con detenimiento reside en que, si afirmamos el carácter constitutivo de la inscripción de la hipoteca, la consecuencia - al parecer inevitable - sería que todo aquello que no estuviera inscrito carecería de la consideración jurídica de hipoteca. La falta de inscripción determinaría, en este caso, la imposibilidad de ejercitar la acción hipotecaria o, por ejemplo, la imposibilidad de acudir al procedimiento del art. 131 de la L.H., así como al ejecutivo ordinario de L.E.C. ${ }^{1}$ ex acción hipotecaria, o al extrajudicial de ejecución hipotecaria.

En relación, por tanto, con el tema que ahora nos ocupa habremos de observar no sólo las prescripciones legislativas al respecto, sino también las diversas interpretaciones que caben sobre las mismas y las diversas posiciones que en torno a ellas haya mantenido tanto la doctrina cuanto la jurisprudencia.

Los preceptos legales en los que habremos de basar nuestro estudio son, como

1 AMORÓS GUARDIOLA destaca en relación con este tema que «al margen de la acción real hipotecaria, sí podrá acudirse al procedimiento ejecutivo ordinario actuando como simple acreedor escriturario, sin garantía real, de acuerdo con el art. 1924-3-A) C.C., sólo con preferencia respecto a los demás bienes muebles e inmuebles del deudor que no estén especialmente afectos al pago en virtud de créditos singularmente privilegiados (arts. 1922 y 1923 C.C).»

AMORÓS GUARDIOLA, M., La publicidad registral de los préstamos hipotecarios. La transmisión de la finca hipotecada, en «Hipotecas y Seguridad Jurídica», Madrid, 1991, p. 34. 
ya se ha mencionado, el art. $1.875-1^{\circ}$ del Código Civil y los arts. 145 y 159 de la Ley Hipotecaria. El tenor literal de tales preceptos es el siguiente:

Art. $1875-1^{\circ}$ C.C.: «Además de los requisitos exigidos en el art. 1.857, es indispensable, para que la hipoteca quede válidamente constituida, que el documento en que se constituya sea inscrito en el Registro de la propiedad».

Art. 145 L.H.: «Para que las hipotecas voluntarias queden válidamente establecidas, se requiere:

$1^{\circ}$ Que se hayan constituido en escritura pública.

$2^{\circ}$ Que la escritura se haya inscrito en el Registro de la Propiedad.

Art. 159 L.H.: «Para que las hipotecas legales queden válidamente establecidas se necesita la inscripción del título en cuya virtud se constituyan».

Como vemos, pues, de los artículos transcritos parece deducirse que en nuestro Ordenamiento Jurídico se impone el carácter constitutivo de la inscripción registral de la hipoteca. Sin embargo, teniendo en cuenta que los preceptos legales han de ser interpretados sistemáticamente y de modo conjunto con el resto de las disposiciones del Ordenamiento ${ }^{2}$, hay autores que - según veremos- niegan tal resultado, desde una interpretación de los mencionados preceptos que atienda al punto de vista histórico, teleológico y sistemático, así como a la voluntad del legislador.

Hoy, fundamentalmente, son dos las corrientes doctrinales que podemos encontrar en relación con la cuestión del carácter constitutivo o no de la inscripción de la hipoteca. Por una parte, tenemos en nuestra doctrina la corriente que bien pudieramos denominar «clásica» - más común y extendida que aquella otra que veremos a continuación-, según la cual, la inscripción es un elemento constitutivo de la hipoteca. Esta teoría es la sustentada, entre otros, por autores como ROCA SASTRE ${ }^{3}$, CHICO Y ORTIZ ${ }^{4}$, CASTÁN ${ }^{5}$, BALLARÍN ${ }^{6}$, AMORÓS

2 Recordemos, en este sentido, que el art. $3^{\circ}$, apartado $1^{\circ}$ del Código Civil establece que: «Las normas se interpretarán según el sentido propio de sus palabras, en relación con el contexto, los antecedentes históricos y legislativos, y la realidad social del tiempo en que han de ser aplicadas, atendiendo fundamentalmente al espíritu y finalidad de aquéllas».

3 «Derecho Hipotecario», $7^{\mathrm{a}}$ edic., Barcelona 1979, T. I, p. 199 y ss.; y T. IV, vol. 1º, p. 277.

4 «Estudios sobre Derecho Hipotecario», T. II, Madrid, 1989, p. 1448 y 1449.

5 «Derecho Civil Español Común y Foral», T. II., vol. II, 12ª edic., p. 423.

6 BALLARÍN HERNÁNDEZ, R. (1980), La hipoteca. (Génesis de su estructura y función), Madrid, pp. 130 a 165 , y 198 a 222.

Es de destacar en el trabajo de este autor el estudio de la evolución legislativa de los preceptos que habremos de analizar en el desarrollo de este tema. 
GUARDIOLA ${ }^{7}$, HERMIDA LINARES ${ }^{8}$ o LALAGUNA ${ }^{9}$. Por otra parte, encontramos también en nuestra doctrina la opinión de aquellos que se muestran partidarios de la tesis opuesta, es decir, de entender que la inscripción de la hipoteca no tiene carácter constitutivo, pues dicha institución jurídica queda configurada por el acuerdo y la voluntad de las partes; si bien, cosa distinta serían, sin embargo, los efectos que frente a terceros pudieran producirse. Entre quienes sustentan esta teoría podemos citar, también a título de ejemplo, a autores como NUÑEZ LAGOS ${ }^{10}$, SANZ FERNÁNDEZ ${ }^{11}$, RAMOS FOLQUES ${ }^{12}$ o GORDILLO CAÑAS ${ }^{13}$.

Basten, pues, estas notas para poder identificar ambas posiciones doctrinales —en las que profundizaremos a continuación-, y para dejar planteado el problema que en lo sucesivo vamos a tratar. Sirva únicamente, como anticipo, el constatar que tras las muchas discusiones habidas, actualmente es bastante fácil encontrar una respuesta sencilla, que la finalidad de este estudio no es otra que la de tratar de «desenredar» y ordenar los argumentos de aquella multiplicidad de opiniones y que hoy es posible afirmar, sin temor a equivocarse, que -como veremos- la inscripción de la hipoteca tiene excepcionalmente en nuestro sistema jurídico carácter constitutivo.

\section{TESIS A FAVOR DEL CARÁCTER CONSTITUTIVO DE LA INSCRIP- CIÓN}

Establecidas de este modo las premisas de las que parte nuestro estudio, comencemos por abordar la que hemos denominado «doctrina clásica», partidaria - como sabemos- del carácter constitutivo de la inscripción registral en la institución de la hipoteca.

7 «La publicidad registral de los préstamos hipotecarios. La transmisión de la finca hipotecada», op. cit.

8 HERMIDA LINARES, M., « ¿Es constitutiva la inscripción en el derecho real de hipoteca?», R.C.D.I., 1949.

9 «Los créditos hipotecarios», en Revista de Derecho Notarial (85-86), julio-diciembre 1974, pp. 109-205.

«Los modos de adquirir la propiedad y los contratos de finalidad traslativa en el Derecho Español», en R.D.P., 1973.

10 «Realidad y Registros», R.C.D.I., 1945.

"El Registro de la Propiedad Español», R.C.D.I., 1949.

11 SANZ FERNÁNDEZ, "Instituciones de Derecho Hipotecario», T. I., Madrid, 1947.

12 «La inscripción y la hipoteca hasta el Código Civil», R.C.D.I., n² 249, 1949.

«La hipoteca y la inscripción después del C.C.», R.C.D.I., n 250, 1949.

«El principio legitimador y la hipoteca», R.C.D.I., $\mathrm{n}^{\circ} 252,1949$.

Estos tres artículos se distribuyeron conjuntamente en una separata que lleva por título « $L a$ hipoteca y la inscripción».

13 GORDILLO CAÑAS, A., «Excerpta en tema de constitución de hipoteca voluntaria», en «Estudios de Derecho Civil en homenaje al Profesor Dr. José Luis Lacruz Berdejo», vol. I, Barcelona, 1992. 


\subsection{La interpretacion literal de los preceptos}

Los defensores de esta teoría se basan, fundamentalmente, en que de la interpretación literal de los preceptos transcritos anteriormente (arts. 1.875 pf. $1^{\circ}$ C.C. y 145 y 159 L.H.) resulta indubitadamente el carácter constitutivo de la inscripción de la hipoteca en el Registro. Esta postura elevada a su máximo exponente conduce a conclusiones como la formulada por CASTÁN al manifiestar que «la hipoteca no inscrita no es válida, no ya con respecto a terceros, sino ni aún entre los interesados» ${ }^{14}$. CHICO Y ORTIZ, partidario igualmente del carácter constitutivo de la inscripción de la hipoteca, considera que dicho carácter de la inscripción registral se incorpora en nuestro Ordenamiento con la redacción del art. 1.875 del C.C. ${ }^{15}$; ello supone, naturalmente, aceptar que la necesidad de inscribir la hipoteca para considerarla constituida es el resultado de una decisión legislativa, es decir se trata de un carácter escogido únicamente por motivos de política legislativa. El problema que plantea GORDILLO CAÑAS en relación con esta interpretación es el de si, efectivamente, nuestro legislador tuvo esa intención cuando incluyó en el conjunto del Ordenamiento Jurídico el art. 1.875 del C.C. Para ello, veamos, aunque muy someramente, cuál ha sido la evolución legislativa en el tratamiento de esta cuestión ${ }^{16}$.

Efectivamente, parece que el carácter constitutivo de la inscripción registral de la hipoteca se incorpora en nuestro Ordenamiento con la redacción e inclusión en el mismo del art. 1.875 del C.C. Este carácter constitutivo había sido desconocido tanto en nuestra historia legislativa ${ }^{17}$ cuanto en los antecedentes más remotos en

14 CASTÁN TOBEÑAS, J., «Derecho Civil Español Común y Foral», T. II, vol. $2^{\circ}, 12^{\mathrm{a}}$ edic., Madrid, 1978, p. 423.

15 Aún así, critica este autor —con toda razón, a nuestro juicio- la redacción del artículo 1.875 , pues en él, las frases «válidamente constituida» y «el documento en que se constituya», «significaban una repetición de principio».

CHICO Y ORTIZ, J.M ${ }^{\mathrm{a}}$, «Estudios de Derecho Hipotecario», op. cit., p. 1.449.

La discusión, por tanto, sobre si es o no constitutiva la inscripción de la hipoteca la centra CHICO en torno a los artículos 145 y 159 de la L.H., pues, si bien el primero de ellos establece que la escritura pública constituye la hipoteca, estableciendo la necesidad de la inscripción para su eficacia, el art. 159, por su parte, establece la necesidad de la inscripción para que las hipotecas legales queden «válidamente establecidas».

16 Un estudio en profundidad de este tema escaparía, sin duda, del objeto de nuestro trabajo. Para un análisis más detenido, puede verse:

BALLARÍN HERNÁNDEZ, R., «La hipoteca. (Génesis de su estructura y función)», Madrid, 1980.

AMORÓS GUARDIOLA, M. (1990), «La publicidad registral de los préstamos hipotecarios. La transmisión de la finca hipotecada», en Hipotecas y seguridad jurídica, Madrid.

GORDILLO CAÑAS, A., «Excerpta en tema de constitución de hipoteca», op. cit.

CANALS BRAGE, F. (1988), «El valor de la inscripción en la hipoteca», en Centenario de la Ley de Bases del Código Civil, Madrid.

17 Así, no existe mención del mismo ni en las antiguas Contadurías u Oficios de hipoteca, ni en la Ley Hipotecaria de 1861. 
los que se inspira nuestro Derecho Hipotecario y Registral ${ }^{18}$. En la Ley Hipotecaria de 1861, actualmente derogada, el art. 146 prescribía $^{19}$ que para que las hipotecas voluntarias pudieran perjudicar a terceros debían haberse constituido en escritura pública, y dicha escritura debía haber sido inscrita en el Registro. En opinión de GORDILLO CAÑAS, no existía en la anterior regulación el más mínimo problema: «la hipoteca se constituye en escritura pública, y desde entonces existe como tal gravamen hipotecario. Pero (...) para que pueda ésta perjudicar a tercero, se requiere que la escritura de su otorgamiento se haya inscrito en el Registro» ${ }^{20}$. Es por ello que -en su opinión- no deja de ser sorprendente la aparición del art. 1.875 del C.C ${ }^{21}$. Esta opinión, sin embargo, no es comúnmente compartida, pues la mayor parte de la doctrina considera que la redacción del art.

18 De hecho, la inscripción constitutiva de la hipoteca era también desconocida en el Derecho Romano, según el cual, «Contrahitur hypotheca per pactum conventum, cum quis paciscatur, ut res eius propter aliquam obligationem sint hyphotecae nomine obligatae: nec ad rem pertinet, quibus fit verbis, sicuti est in his obligationibus quae consensu contrahuntur. et ideo et sine scriptura si convenit ut hipotheca sit et probari poterit: et sine his autem valet quod actum est, si habeat probationem: sicut et nuptiae sunt, licet testationes in scriptis habitae non sunt» (D. 20,1,4, Gai. ad formul. hypothec.).

«Se contrae la hipoteca por medio de pacto cuando alguien acuerda que algunas cosas suyas queden sujetas a título de garantía hipotecaria en virtud de una obligación, no importando al caso los términos de la declaración con que se haga, como sucede también en las declaraciones que se contraen por el consentimiento; por ello, aunque se convenga sin escritura, si la hipoteca se puede probar, la cosa acerca de la cual se pactó queda sujeta como garantía; pues se hacen las escrituras de hipoteca para que pueda probarse más fácilmente lo convenido, pero lo acordado vale aún sin escritura, si se tiene un medio de prueba, como sucede con el matrimonio, aunque no se tengan testimonios por escrito.»

IGLESIAS REDONDO, J. (1986), «Repertorio bilingüe de definiciones, reglas y máximas jurídicas romanas», Madrid, p. 69.

19 Literalmente, el art. 146 L.H. (de la L.H. de 1861) establecía que:

«Para que las hipotecas voluntarias puedan perjudicar a tercero se requiere:

Primero: Que se hayan convenido o mandado constituir en escritura pública.

Segundo: Que la escritura se haya inscrito en el Registro que se establece por esta Ley.»

20 GORDILLO CAÑAS, A., «Excerpta en tema de constitución de hipoteca voluntaria», op. cit., p. 429.

21 «He aquí un precepto, sin paternidad conocida (...) y problemático en muchos aspectos: Problemático en su redacción, al introducir literalmente una doble instancia constitutiva, lógicamente imposible. Problemático también en su integración, tanto en el sistema general de inscripción declarativa, que se mantiene inalterado (art. 606 C.C.), como en el conjunto de la regulación de la hipoteca, que tampoco ahora se retoca. Y problemático finalmente y como no podía ser de otro modo, en su explicación».

GORDILLO CAÑAS, «Excerpta en tema de constitución de hipoteca voluntaria», op. cit., p. 429.

También en relación con el precepto $1.875-1^{\circ}$ sostiene RAMOS FOLQUÉS que «el párrafo es antiacadémico y marañoso. Antiacadémico, por la repitición del constitutivo, que viene a denunciar la existencia de dos claustros alumbrando una misma cosa, desviándose con ello de la Naturaleza, que sólo admite que de un mismo claustro nazcan dos o más seres. Es marañoso porque estando colocado en el libro de los contratos, se inscribió para el de los derechos reales. Trastueque que ha embrollado los espíritus y enredado las ideas».

RAMOS FOLQUÉS, R., «la hipoteca y la inscripción», en R.C.D.I. núms. 249, 250 y 252, año 1949. 
1.875 del Código fue conveniente e incluso necesaria. Así, a título de ejemplo, podemos citar a AMORÓS GUARDIOLA que nos habla de «la acertada innovación llevada a cabo por el C.C. frente al texto anterior de la L.H.»22; también, entre otros, GARCÍA GARCÍA, cuando comenta el art. 1.875 C.C., pone de manifiesto el acierto que supuso establecer en él el carácter constitutivo de la inscripción hipotecaria ${ }^{23}$.

No obstante, en defensa del carácter constitutivo de la inscripción de la hipoteca se han vertido también otro tipo de argumentos, de los que nos ocuparemos a continuación, alejados absolutamente de meras interpretaciónes literales en torno a la normativa vigente.

\subsection{Cuatro corrientes doctrinales}

Para continuar con el estudio del tema que nos ocupa vamos a seguir, en cierta medida, el esquema de trabajo utilizado por GORDILLO CAÑAS ${ }^{24}$. Este autor agrupa en tres corrientes las distintas teorías que, en su opinión, vienen entendiendo la inscripción de la hipoteca como elemento constitutivo de tal institución jurídica. Junto a las tres corrientes a las que él hace mención vamos a añadir nosotros una cuarta postura que sería la única en la que, en opinión del propio autor, podría basarse la justificación del carácter constitutivo de la inscripción de la hipoteca. Veamos, pues, en qué consiste cada una de estas corrientes doctrinales.

\subsubsection{La inscripcion de la hipoteca como modo de adquirir la propiedad (sustitu- to de la «datio rei»)}

En nuestra doctrina hay autores que se muestran partidarios de entender la inscripción de la hipoteca como «modo» de adquirir la propiedad. Para ellos, la

22 Este autor entiende - cuando busca las razones de «esta acertada innovación»- que «parece razonable pensar que en la L.H. no se había llegado a establecer ese criterio de la inscripción constitutiva (criterio - añade- perfectamente comprensible hoy para una mentalidad moderna) porque los legisladores que introdujeron el nuevo sistema de Registro tuvieron principalmente la preocupación de establecer los principios de publicidad de las hipotecas - para excluir las antiguas hipotecas tácitas-y de especialidad de las mismas- para impedir las hipotecas generales».

AMORÓS GUARDIOLA,M., «La publicidad registral de los préstamos hipotecarios. La transmisión de la finca hipotecada», op. cit., p. 25.

23 GARCÍA GARCÍA, J.M., «Comentario del Código Civil», Madrid, 1991, p. 1898.

«Una de las innovaciones más trascendentales del C.C. respecto a la legislación hipotecaria entonces vigente, fue establecer el carácter constitutivo de la inscripción de hipoteca, de tal modo que ésta no nace sino a partir de la inscripción, y ello no sólo respecto a terceros, como decía la L.H. de 1861, sino incluso entre partes (...). A pesar de la posición crítica de algún autor, la implantación de la inscripción constitutiva en materia de hipotecas es uno de los mayores aciertos del C.C., con una visión claramente hipotecarista, más allá de lo que tuvieron los redactores de la L.H. de 1861.»

24 GORDILLO CAÑAS, «Excerpta en tema de constitución de hipoteca voluntaria», op. cit,, pp. $441-450$. 
inscripción de la hipoteca en el Registro viene a suplir la necesaria carencia que tiene lugar en la hipoteca, en relación con el elemento - también constitutivode la tradición, que se da en el resto de nuestros derechos reales posesorios. Así opina, por ejemplo, ROCA SASTRE cuando establece que:

«(...)como en el derecho real de hipoteca no cabe tradición, porque la posesión es totalmente ajena a él, la ley ha sustituido ésta por la inscripción en el Registro de la Propiedad y estamos conformes con esta idea porque como la tradición es elemento constitutivo para la transmisión del dominio y demás derechos reales de inherencia posesoria, la ley en la hipoteca ha sustituido simplemente el elemento constitutivo de la tradición por el elemento también constitutivo de la inscripción» ${ }^{25}$.

En este mismo sentido, aunque de un modo mucho más explícito, se manifiesta LALAGUNA ${ }^{26}$, quien se muestra abiertamente partidario de incluir la inscripción constitutiva en la enumeración que realiza el Código Civil sobre los modos de adquirir la propiedad (art. 609 C.C.) ${ }^{27}$.

GORDILLO CAÑAS, en absoluto partidario de la teoría expuesta, centra en cuatro puntos su argumentación en contra. En primer lugar, «a nuestro propósito - dice - basta con indicar que si no es del todo cierto ni absolutamente pacífico que la hipoteca constituya propiamente un derecho real $^{28}$, mal podrá fundamentar-

25 ROCA SASTRE, «Derecho Hipotecario», op. cit., T. I., p. 204.

26 LALAGUNA, E., «Los modos de adquirir la propiedad y los contratos de finalidad traslativa en el Derecho español», en R.D.P., 1973.

27 «Antes de concluir esta revisión, y ante la perspectiva de una reforma del Código, parece conveniente llamar la atención acerca de la oprotunidad de incluir en el texto del artículo comentado (art. 609 C.C.) una referencia a la inscripción, en los casos en que tiene carácter constitutivo. En el momento de promulgarse el Código, sólo tiene carácter constitutivo la inscripción relativa al derecho real de hipoteca (...)».

LALAGUNA, op. últimamente cit., p. 392.

28 El estudio de si la hipoteca es o no un derecho real escapa, naturalmente, de los fines de este trabajo. No entraremos por tanto a demostrar por qué entendemos que la hipoteca es efectivamente un derecho real, pero dado que, modestamente, así lo entendemos huelga decir que no compartimos en absoluto, el primero de los razonamientos de GORDILLO CAÑAS contra la tesis de la inscripción constitutiva de la hipoteca por asimilación de ésta con los modos de adquirir la propiedad.

Sin ánimo de profundizar en el tema de la naturaleza jurídica de la hipoteca sino simplemente con la intención de dejar apuntadas algunas notas bibliográficas, téngase en cuenta que en torno a este tema cuatro han sido las corrientes doctrinales más significativas:

- La de quienes entienden que la hipoteca es un derecho real; vid. por todos ROCA SASTRE, Derecho hipotecario, T. VI.2, $7^{\text {a }}$ ed., Barcelona 1979, p. 237 y ss.

- La llamada «teoría procesalista de la hipoteca»; al respecto puede verse CARNELUTTI, «Natura giuridica dell'ipoteca» en Rivista di Diritto Processuale Civile, 1939, pp. 3 a 21; FENECH, «recepción de la hipoteca en el Derecho Procesal», en Revista de Derecho Procesal, 1952, año VIII, $n^{\circ} 4$, pp. 377 a 422; CARRERAS, El embargo de bienes, Barcelona 1952; CÁMARA, «Notas críticas sobre la naturaleza jurídica de la hipoteca como derecho real» en Revista de Derecho Privado, 1949, pp. 377 a 422 . 
se la necesidad de su inscripción, llevando su nacimiento al sistema general de los derechos reales» ${ }^{29}$. El segundo de los argumentos, lo desarrolla este autor a partir de la hipótesis de admitir «que la hipoteca constituyera un auténtico y propio derecho real», y el problema que se plantearía en este caso, según él, sería el de que «al no ser la hipoteca un derecho real posesorio (...) ¿qué sentido puede tener, entonces, someterla en el momento de su nacimiento a un régimen general que ningún otro momento ni aspecto le cuadra?» $\gg^{30}$. En tercer lugar, GORDILLO CAÑAS razona del siguiente modo, «pero admitamos que se la somete. Aún así tendríamos que preguntarnos: ¿Por qué ha de ser la inscripción registral y no la escritura pública, la que venga a cumplir en el nacimiento de la hipoteca la función de modo o entrega, cuando en nuestro Derecho es dicha escritura la que parece llamada a suplir la entrega (arts. 1.462, 1.464 C.C.)?» ${ }^{32}{ }^{33}$. Y, por último, en cuarto lugar, «el argumento definitivo en esta materia es —según GORDILLO CAÑAS - la imposibilidad de someter el nacimiento de la hipoteca al sistema del título y el modo. El contrato de hipoteca es un contrato inmediatamente real ${ }^{34}$, (...)lo que por definición significa que sin intermediación de conducta debida produce la mutación jurídico-real correspondiente (...) por pura definición o acuerdo, sin necesidad de entrega: $¿$ a qué, pues, suplir ésta mediante la inscripción cuando la entrega, más que innecesaria, es absolutamente ajena a la constitución

— La de quienes entienden la hipoteca como una obligación «ob rem»: vid., por todos CROME, System, III, p. 639 y ss.

- La teoría abolicionista entre los derechos reales y los de obligación; al respecto puede verse GIORGIANI, «Diritti reali» en «Novisimo Digesto Italiano», V, pp. 749 y ss.; en la doctrina española, con algunas variaciones VALLET DE GOYTISOLO, J., Panorama del Derecho Civil, Barcelona, 1973.

29 GORDILLO CAÑAS, «Excerpta ... «, op. cit., p. 443.

30 GORDILLO CAÑAS, «Excerpta ...», op. cit., p. 442.

31 Tal vez, la razón pueda estar en que, precisamente por no tratarse de un derecho real posesorio (aunque sí de un derecho real), de algún modo habrá de buscarse la seguridad jurídica que en los posesorios genera el simple disfrute de la posesión.

32 GORDILLO CAÑAS, op.cit., p. 441.

33 La solución que ROCA SASTRE da a preguntas de contenido similar a la formulada por este autor, es la siguiente: «la opinión (...) de que éste queda válidamente constituido (se refiere al derecho de hipoteca) con el otorgamiento de la escritura pública y que la falta de inscripción se limita a suspender su eficacia, no puede reputarse acertada, ya que si el art. 1.429 de la Ley de Enjuiciamiento Civil, atribuye el carácter de título ejecutivo a la primera copia de la escritura pública, debe tenerse en cuenta que se tratará de un juicio ejecutivo en el que se hará valer la acción personal derivada del crédito que se habrá querido garantizar con la hipoteca y, por consiguiente, será un ejecutivo sólo posible entre quienes sean partes en la relación de derecho y deber propio del crédito asegurado, pero la inscripción es necesaria para ejercitar el derecho frente a terceros, por lo que dicha inscripción es propiamente constitutiva».

ROCA SASTRE, «Derecho Hipotecario», op. cit., T. I., p. 207.

34 Recordemos aquí, que esto es lo que el autor puso en duda en el primero de sus argumentos; que el derecho de hipoteca fuera, efectivamente, un derecho real. 
del derecho nacido del contrato inmediatamente dispositivo o real quoad effectum?» $\gg^{35}$.

\subsubsection{La inscripcion de la hipoteca como sustituto de la «datio rei»}

La siguiente de las corrientes doctrinales defensoras del carácter constitutivo de la inscripción registral de la hipoteca es, a juicio de GORDILLO CAÑAS, aquella según la cual «en la hipoteca, donde al no ser ésta garantía posesoria, no puede haber entrega, la «datio rei» sería suplida por la inscripción registral, de la que resultaría a la hipoteca su publicidad artificial y provocada. La inscripción registral, de tal modo, vendría a suplir, no a la entrega (traditio) constitutiva del modo en el sistema de adquisición de los derechos reales, sino a la entrega, datio rei, determinante de la perfección del contrato real. Al asimilarse así a éste el contrato de hipoteca se habría convertido en un contrato en cierto modo formal: su perfección vendría a situarse en su inscripción registral, y la inscripción presenta naturaleza próxima a la de la forma del contrato ${ }^{37}$. Esta es, dice el autor, la postura mantenida por NÚÑ̃Z LAGOS ${ }^{38}$. Sin embargo, nosotros nos mostramos de acuerdo con la interpretación que ROCA SASTRE hace de este mismo autor (Nuñez Lagos) $^{39}$, y consideramos que en la postura mantenida por él en el mencionado artículo, no sólo no está justificando el carácter constitutivo de la inscripción de la hipoteca, sino que niega, en realidad, la existencia de tal carácter. Para NÚÑEZ LAGOS, los derechos reales «nacen» ${ }^{40}$ antes de llegar al Registro y, por tanto, la inscripción de la hipoteca, como necesaria o no, es un problema que afecta a la «forma» del negocio jurídico, pero no al principio de inscripción; dicho principio, en su opinión, afecta no sólo a la constitución de los derechos reales, sino también a la eficacia del asiento en sí. Según este autor, no hay ninguna diferencia una vez inscritos los asientos de hipoteca y un asiento cualquiera de otro derecho real, porque en los dos supuestos la eficacia deriva del título inscrito a través del asiento.

35 GORDILLO CAÑAS, «Excerpta ...», op. cit., p. 443.

36 Esta última crítica del autor a las tesis que pretenden justificar la inscripción constitutiva de la hipoteca por el paralelismo que tal hecho supone en relación con la tradición en el resto de derechos reales, será objeto de comentarios más detallados al final de la exposición de las distintas posiciones doctrinales en torno a este tema. A modo de avance, baste simplemente con señalar ahora, que, efectivamente, en nuestra opinión, tal vez no sea necesario acudir a la asimilación inscripción en la hipoteca - tradición en los derechos reales posesorios, para poder justificar el carácter constitutivo de la inscripción hipotecaria.

37 GORDILLO CAÑAS, «Excerpta ...», op. cit., p. 444.

38 NÚÑEZ LAGOS, «Realidad y Registro», op cit., p. 422.

39 ROCA SASTRE, «Derecho Hipotecario», op. cit., T. I. p. 200:

«NUÑEZ LAGOS niega que en nuestra legislación pueda hablarse de inscripción constitutiva en materia de hipoteca.»

40 Con lo cual nos está diciendo que la inscripción no es constitutiva de la hipoteca. 
En el capítulo de las críticas que pudieran hacerse a la posición mantenida por este autor vamos a referirnos únicamente a la que le dirige ROCA SASTRE, pues la formulada por GORDILLO CAÑAS no parece la más plausible, por las razones que se acaban de apuntar. Para ROCA SASTRE, «no es argumento serio decir que una vez inscritos los respectivos títulos de hipoteca o de otro cualquier derecho real, no hay diferencia en cuanto a la eficacia de uno y otro asiento, porque la eficacia deriva en ambos supuestos del título inscrito a través del asiento, y no es serio porque es tan evidente que no hay diferencia que es inútil esgrimirlo como argumento, pues de lo que se trata en materia del valor constitutivo de la hipoteca es averiguar precisamente todo lo contrario, es decir, si antes de la inscripción existe o ha nacido ya la hipoteca, del mismo modo que existe o ha nacido otro derecho real» ${ }^{41}$.

\subsubsection{La inscripción de la hipoteca como imperativo legal cuya contravención implica la nulidad}

La tercera de las corrientes que defienden, en opinión de GORDILLO CAÑAS, el carácter constitutivo de la inscripción en la figura de la hipoteca, sería aquella que entiende que «la inscripción es necesaria (...) porque su omisión implica la nulidad de la hipoteca por contravención de ley imperativa ${ }^{42}$. Cita el autor, como representante de esta doctrina a MANRESA, para el cual, y con base en una interpretación literal del código (que establece la inscripción como requisito de validez del acto), la inscripción es necesaria, puesto que sin ella la hipoteca resultaría nula. A esta toería se opone RAMOS FOLQUES; según este autor no es posible sostener que una hipoteca deviene nula por carecer de inscripción. ${ }^{43}$ Para RAMOS FOLQUES, la palabra «validez» utilizada en el Código, se opone a «ineficaz» (no a «invalidez o nulidad). La inscripción es según el código un elemento «indispensable», pero no «esencial» (esenciales serían la accesoriedad,

41 ROCA SASTRE, «Derecho Hipotecario», op. cit., T.I., pp. 206 y 207.

42 GORDILLO CAÑAS, «Excerpta ...», op. cit., p. 448.

43 «No compartimos el criterio de que según el Código, es nula la hipoteca mientras la inscripción no tenga lugar. Hay un término medio que consiste en la suspensión de efectos hasta la ejecución de un requisito legal».

A continuación, añade este mismo autor, que en relación con el criterio que sostiene «que en tanto no se practique la inscripción, el contrato de hipoteca se equipara a la promesa de hipoteca, tampoco podemos - dice - compartir ese criterio, por que entonces ¿para qué se puso en el Código el art. 1.862 ?

El art. 1.875 del Código seguramente lo que quiso decirnos es que la hipoteca configurada o establecida por el contrato no queda eficazmente establecida hasta que se opere la inscripción.

El contrato de hipoteca como todos los contratos, para ser admitido en el Registro de la Propiedad, ha de existir y ser válido».

RAMOS FOLQUÉS, R. (1949), «la hipoteca y la inscripción después del Código Civil», R.C.D.I., $\mathrm{n}^{\circ} 250$. 
la capacidad y la facultad dispositiva del contrayente) $)^{44}$. También GORDILLO CAÑAS critica la concepción de la inscripción constitutiva que sostienen quienes entienden que debe ser así porque de lo contrario se estaría violando una ley imperativa. La argumentación de este último autor se centra, fundamentalmente, en que - en su opinión - el problema en materia de inscripción de la hipoteca no discurre en nuestro Ordenamiento por el cauce de la imperatividad legal y la sanción de su incumplimiento ${ }^{45}$.

Hasta ahora hemos expuesto las tres teorías fundamentales que en, opinión de GORDILLO CAÑAS, se han construido en el ámbito de nuestra doctrina en defensa del carácter constitutivo de la inscripción registral de la hipoteca. Frente a dichas teorías se han ido exponiendo también las críticas que otros sectores doctrinales y el propio GORDILLO CAÑAS les han dirigido. Pero llegados a este punto del trabajo, la pregunta obvia es cuál es entonces la opinión de este autor en torno al tema que nos ocupa.

\subsubsection{La inscripción de la hipoteca como «conditio sine qua non» o «conditio iuris»}

En opinión de GORDILLO CAÑAS, «si el valor constitutivo de la inscripción de la hipoteca no aparece intrínsecamente justificado por ninguno de los capítulos anteriores, sólo queda entender que, por pura voluntad del legislador, se le ha elevado en nuestro derecho a la condición de presupuesto legal de existencia, «conditio sine qua non o conditio iuris» de la hipoteca» ${ }^{46}$.

El problema que plantea este autor, es que en su opinión, no puede deducirse

$44 \mathrm{Al}$ decir el artículo 1.875 del Código que la validez de la hipoteca establecida por el contrato depende de la inscripción, más bien da idea de que la inscripción viene a ser como un bautismo purificador; de un «ratum facere»; ratificación o confirmación; de un «legitimum reddere», legitimar o dar legitimación.

Y si la inscripción no aparece, según el mismo artículo fundador de la teoría constitutiva, exigida como requisito esencial sino como requisito indispensable para la validez de la hipoteca contractual, su encuadramiento jurídico corresponde con las llamadas condiciones impropias o «conditio legis».

RAMOS FOLQUÉS, «La hipoteca y la inscripción ...», op. cit.

45 « ¿Se nos dirá que los arts. 313 a 315 de la Ley Hipotecaria implican una forma de sanción a la omisión de la inscripción? No tendríamos inconveniente en admitirlo, pero reconózcase que esa forma de reacción, sustantivada en su peculiaridad, es bien distinta a la de la nulidad radical del acto 'contra legem'».

GORDILLO CAÑAS, «Excerpta ...», op. cit., p. 449.

46 GORDILLO CAÑAS, «Excerpta ...», op. cit., p. 449.

A continuación, aclara el autor que «La calificación de algo como «conditio juris» equivale a decir que ese algo - en este caso, la inscripción de la hipoteca- es necesario pura y simplemente porque así lo impone el legislador, sin que de suyo venga exigido por imperativo de los lógicoexplicativos del sistema». 
de nuestros cuerpos legales una voluntad clara del legislador de instaurar en la hipoteca la inscripción constitutiva ${ }^{47}$.

Recordemos que en un principio se hizo referencia a los diversos autores que se mostraban contrarios al carácter constitutivo de la inscripción de la hipoteca en el Registro y que entre ellos se situó a GORDILLO CAÑAS. Entiéndase que el situarlo ahora aquí se debe sólo a que según él, si se pretende afirmar que la inscripción de la hipoteca tiene carácter constitutivo ello habrá de hacerse desde una óptica puramente formal pero que en absoluto responderá a criterios lógicos. Se trata simplemente de una opción de política legislativa pero que ni siquiera, según él, se ha sabido reflejar con propiedad en nuestros cuerpos legales.

Analizada así esta última perspectiva, hasta este momento hemos hecho referencia a uno sólo de los aspectos de la polémica a tratar. No obstante, antes de observar en qué se basan quienes entienden que la inscripción registral en materia hipotecaria no tiene carácter constitutivo, entendemos que sería conveniente determinar qué se entiende por «inscripción constitutiva».

\section{SIGNIFICADO DE LA EXPRESIÓN «INSCRIPCIÓN CONSTITUTI- VA»}

Como hemos tenido ocasión de ver anteriormente, la redacción e introducción en nuestro Ordenamiento Jurídico del art. 1.875 C.C. supuso un cambio legislativo de suma importancia, en el sentido de que fue a raíz de su entrada en vigor cuando comenzó a considerarse, por un amplísimo sector doctrinal, que la inscripción de la hipoteca tenía carácter constitutivo. Llegados a este punto creemos conveniente precisar qué debe entenderse por «carácter constitutivo» de la inscripción en el contexto en el que venimos utilizando tal expresión. Realizar esta aclaración, se presenta como un paso previo y necesario que debemos abordar para determinar si, efectivamente, la inscripción de la hipoteca tiene o no el mencionado carácter.

Cuando se utiliza la expresión «inscripción constitutiva», ha de tenerse en cuenta que dicha expresión puede ser entendida de dos modos distintos: en sentido propio - que supone que la hipoteca nace desde el momento de la inscripción y por la existencia de dicha inscripción-; o, como sostiene GORDILLO CAÑAS, «en un sentido menos propio y más relajado», «entendiendo por tal aquella que, aunque por sí no constituya al derecho, es de tal forma necesaria en el proceso de su nacimiento, que sin ella no se le puede entender constituido ${ }^{48}$.

47 «Si nuestro legislador intentó, con la redacción del artículo 1.875 del C.C. y ulteriores retoques a los originarios 146 y 159 de la Ley Hipotecaria, instaurar un sistema de inscripción constitutiva en materia de hipoteca creemos que su intento resultó objetivamente fallido».

GORDILLO CAÑAS, «Excerpta ...», op. cit., p. 450.

48 GORDILLO CAÑAS, «Excerpta ...», op. cit., p. 441. 
De estas dos acepciones con que se nos presenta la expresión «inscripción constitutiva», parece que, en el marco de nuestro Ordenamiento Jurídico, sólo podríamos utilizar aquella que se ha caracterizado como «inscripción constitutiva en un sentido menos propio». La razón reside, fundamentalmente, en que entender que la inscripción es constitutiva en sentido propio, supone - $-\mathrm{y}$, en esto nos mostramos de acuerdo con GORDILLO CAÑAS- admitir que existe una desvinculación, en el momento del nacimiento de la hipoteca, entre dicho nacimiento y el negocio jurídico de Derecho Civil del que la hipoteca trae su causa ${ }^{49}$.

Una vez fijado el alcance que podemos dar en el marco de nuestro Ordenamiento a la expresión «inscripción constitutiva» creemos haber resuelto el problema que se nos presentaba como paso previo necesario y cuya solución nos condicionaba para poder continuar con el estudio de si la inscripción de la hipoteca, en nuestro Derecho, tiene, o no, carácter constitutivo (naturalmente, entendiendo el carácter constitutivo en este segundo sentido «más relajado» de la expresión, pues como hemos visto, el primero de los dos sentidos -0 , sentido propio-, carece de fundamento en el marco de nuestro Ordenamiento Jurídico). Llegados a este punto del trabajo nos encontramos ya en situación de poder observar con mayores elementos de juicio si, en el ámbito de nuestro Sistema Jurídico, es posible negar a la inscripción de la hipoteca el carácter de constitutiva.

\section{TESIS EN CONTRA DEL CARÁCTER CONSTITUTIVO DE LA INS- CRIPCIÓN DE LA HIPOTECA}

De los diversos autores que al comienzo de este estudio fueron mencionados por sus opiniones contrarias al carácter constitutivo de la inscripción registral en materia hipotecaria vamos a desarrollar a continuación la postura mantenida por RAMOS FOLQUÉS ya que ella es, en nuestra opinión, ejemplificadora de todas las demás. Téngase en cuenta también que, durante el desarrollo de este trabajo, se ha hecho referencia a alguna otra opinión doctrinal al respecto, como la de NÚÑEZ LAGOS (vid. nota $\mathrm{n}^{\circ} 40$ ).

No obstante, antes de dar paso al estudio de la doctrina de RAMOS FOLQUÉS recordemos aquí que, según hemos convenido, la expresión «inscripción constitutiva» debía ser utilizada, mejor que en un sentido propio, en un sentido «más

49 GORDILLO CAÑAS añade a esto que «En tal sentido, ni siquiera en el BGB, ni mucho menos en el suizo (donde la Einigung es sustituida por el negocio causal, y el derecho real existe desde la inscripción, pero no por la inscripción), la inscripción llega a ser constitutiva. En nuestro sistema donde los derechos reales nacen y se adquieren fuera del Registro y según la teoría del título y el modo; donde el Registro lo es, no de actos y contratos, sino de títulos, y dónde la registración se produce bajo el principio de legalidad - lo que implica la previa existencia de título acabado y perfecto- no es posible pensar en inscripción propiamente constitutiva».

GORDILLO CAÑAS, «Excerpta ...», op. cit, p. 440. 
relajado», de modo que «inscripción constitutiva» no significara que la hipoteca nacía «por» la inscripción, sino que dicha inscipción se plantea «de tal forma necesaria en el proceso de su nacimiento, que sin ella no se le puede entender constituido».

El motivo de traer ahora estos extremos a colación, es que según se desprende de lo que hemos visto durante el desarrollo del trabajo, RAMOS FOLQUÉS se muestra contrario a la inscripción constitutiva de la hipoteca y, en nuestra opinión, bien pudiera parecer que lo que en realidad está negando es el entender la expresión en ese «sentido propio» al que tanto nos hemos referido. Tal vez no distinga dicho autor entre las dos acepciones en que podría entenderse la inscripción constitutiva; $o$, al menos, eso parece desprenderse de algunas de sus manifestaciones, como, por ejemplo, cuando sostiene:

«De aquí que la palabra validez del art. 1.875 del Código no pueda tener como contrapartida la de invalidez o nulidad sino la de ineficaz, que quiere decir falta de actividad o potencia. El mismo Código, que ha determinado cuáles son los requisitos esenciales a todo contrato, al referirse concretamente a la hipoteca, dice que, para él, son esenciales los relativos a la accesoriedad, capacidad y facultad dispositiva del constituyente, pero no aplica la palabra «esencial» para la exigencia de la inscripción, sino la palabra «indispensable» como denotando más bien un requisito obligatorio o forzoso. [lo que se ha llamado inscripción constiutiva en sentido débil]

Al decir el artículo 1.875 del Código que la validez de la hipoteca establecida por el contrato depende de la inscripción, más bien da idea de que la inscripción viene a ser como un bautismo purificador; de un «ratum facere», ratificación o confirmación; de un «legitimum reddere», legitimar o dar legitimación».

Es, fundamentalmente, el párrafo que a continuación se va a transcribir, el que nos hace pensar que RAMOS FOLQUÉS no distinguió entre el sentido fuerte y el sentido débil de la «inscripción constitutiva»:

«Y si la inscripción no aparece, según el mismo artículo fundador de la inscripción constitutiva, exigida como requisito esencial, sino como requisito indispensable para la validez de la hipoteca contractual [justo lo que, en un sentido débil, se ha entendido por inscripción constitutiva], su encuadramiento jurídico corresponde con las llamadas condiciones impropias o conditio legis $»^{50}$.

50 RAMOS FOLQUÉS, R., «La hipoteca y la inscripción», op. cit., p. 39.

Las frases entre corchetes son nuestros. 
Y, a lo expuesto, podemos añadir las palabras de GARCÍA GARCÍA (partidario abiertamente del carácter constitutivo de la inscripción hipotecaria), cuando establece que «es preferible esta calificación [la de inscripción constitutiva] a la de condicio iuris, pues, a diferencia de la condición, la inscripción no se retrotrae a la fecha del documento» ${ }^{51}$.

Vemos pues cómo la teoría de RAMOS FOLQUÉS, si bien no puede reconducirse a la teoría partidaria de la inscripción constitutiva en sentido propio, tampoco puede —según lo señalado por GARCÍA GARCÍA - reconducirse a la conditio legis (como el propio autor pretendía). Por ello, entendemos que tal vez, si dicho autor hubiera tenido en cuenta la distinción de los dos significados en que se puede entender la expresión inscripción constitutiva (y hubiera aceptado el sentido más relajado), su teoría no quedaría tan lejos de lo que se entiende por constitutivo en sentido débil.

\section{ALGUNAS CONCLUSIONES. EL ART. 1.875 C.C. Y LOS DOS SENTI- DOS DE LA EXPRESIÓN «INSCRIPCIÓN CONSTITUTIVA»}

Expuestas -ahora sí- las distintas opiniones sobre este tema, así como la posible interpretación que acabamos de ver en torno a una de ellas (la de RAMOS FOLQUÉS), vamos a tratar de esbozar alguna conclusión o, al menos, manifestar cuál es nuestra opinión en torno a este controvertido análisis.

En principio, estamos de acuerdo con quienes han reconocido que la innovación producida por la entrada en vigor del art. 1.875 del C.C. (estableciendo el carácter constitutivo de la inscripción de la hipoteca) es digna de alabanza; si bien la pésima redacción del mismo, unánimemente reconocida, y la mala armonización del conjunto del Ordenamiento con dicho precepto, es merecedora del mayor reproche. En nuestra opinión son éstas las causas fundamentales (mala redacción y mala armonización con el resto de las disposiciones legales) de la diversidad de posiciones doctrinales. Posiblemente, si el art. 1.875 (que, recordémoslo, fue el causante del cambio de orientación legal en torno al carácter de la inscripción en la hipoteca) hubiera modificado el criterio legal imperante hasta ese momento de un modo claro, tajante, acorde con el resto de los preceptos y que no dejara lugar a dudas, la polémica doctrinal hubiera sido menor y la labor de los intérpretes, posiblemente, unánime. En cualquier caso, parece que los requisitos que acabamos de echar en falta en la redacción de este crucial artículo del Código, se nos presentan como exigibles de toda modificación legislativa, especialmente cuando tal modificación supone un cambio de criterios u orientaciones legales de la envergadura del que ahora nos ocupa.

51 GARCÍA GARCÍA, J.M., «Comentario del Código Civil», op. cit., p. 1.898. 
Por otra parte, prueba de que la clave del problema que se ha planteado en torno al carácter de la inscripción de la hipoteca trae su causa de la mala regulación del mismo, es que — según hemos visto- la mayor parte de los autores que cuestionan que la inscripción en la hipoteca sea constitutiva, fundamentan sus tesis en interpretaciones literales y/o sistemáticas y/o históricas del art. 1.875. Sin embargo, se echa de menos una interpretación de carácter teleológico porque si atendemos a la finalidad de la hipoteca y observamos su incidencia sobre el crédito territorial así como la cantidad ingente de negocios jurídicos colaterales que se pueden dar en torno a ella, es evidente que razones de seguridad jurídica nos obligan a hacer accesible al público conocimiento si sobre un determinado inmueble recae o no el peso de una hipoteca. Y ello es necesario no sólo con respecto a terceros (como sucedía en el art. 146 de la L.H. de 1.861), sino que dada la importancia de la institución jurídica que en estos momentos estudiamos, así como sus repercusiones económicas, entendemos digna de elogio la extensión operada con el art. 1.875 que hace necesaria la inscripción para que la hipoteca se constituya no sólo frente a terceros sino también «inter partes». Pero, veamos por qué entendemos que con la entrada en vigor del mencionado precepto se produce, efectivamente, tal extensión.

En primer lugar, recordemos que cuando hablamos de inscripción constitutiva, utilizamos la expresión en su sentido «menos propio» o «más relajado»; es decir que, con ello, entendemos que se trata de un requisito de validez necesario para que esa hipoteca que las partes han acordado constituir, pueda desplegar sus efectos; es decir, «funcionar» como tal hipoteca. Sin embargo, en nuestra opinión, el art. $1875-1^{\circ}$ recoge la expresión «constitutiva» en las dos acepciones que ésta puede tener: así, cuando se refiere al «documento en que se constituya», utiliza la expresión en un sentido propio, y ello porque por dicho documento queda constituida la hipoteca; sin embargo cuando establece el requisito de la inscripción como «indispensable para que la hipoteca quede válidamente constitutida», entendemos que utiliza la expresión en un sentido más relajado, puesto que según el propio precepto ha establecido, la hipoteca quedó propiamente constituida por la voluntad de las partes puesta de manifiesto en ese «documento» que se habrá de inscribir. La inscripción se presenta, por tanto, como un requisito necesario en el momento de la entrada de la hipoteca en el mundo jurídico. Sin inscripción, la hipoteca no puede «funcionar» y, en ese sentido, la inscripción es constitutiva, pues, por muy de acuerdo que estén las partes, se tiene a la hipoteca por jurídicamente inexistente en tanto no se cumpla con ese requisito indispensable. Esta idea de que en el art. 1.875 del Código se contienen las dos acepciones de la palabra constitutiva, y que la inscripción hace referencia al sentido débil, parece venir avalada por el art. 159 de la L.H. cuando establece que «para que las hipotecas legales queden válidamente establecidas se necesita la inscripción [sentido más relajado de la expresión] del título en cuya virtud se constituyan» [inscripción en sentido propio]. 
Sin la inscripción no podemos decir que la hipoteca no exista (existe, precisamente, porque entendemos la expresión «inscripción constitutiva» en un sentido débil), lo que sucede es que como se ha dicho «no funciona».

Veámoslo con un ejemplo que puede ilustrar bastante esta idea -aunque, como sabemos, las comparaciones sean odiosas-:

Imaginemos que tenemos las diversas piezas que conforman un coche; imaginemos que queremos, podemos y sabemos construir un coche; imaginemos, por último, que lo construimos. Sin embargo, una vez que tenemos el coche construido, es requisito necesario para que pueda cumplir la función que le es propia, proceder a su matriculación. Se trata de un «baño formal» de carácter necesario para poder dedicar el coche al fin que le es propio, para que pueda «funcionar» como tal coche. Pues bien, «salvando las distancias», podría pensarse que con la hipoteca sucedería algo parecido: si tenemos todo lo necesario para constituir una hipoteca y la constituimos, la hipoteca existe, pero existe «sin vida jurídica», y puesto que la hipoteca no es una entidad objetiva (como pudiera ser el coche), sino jurídica, tal hipoteca sólo tiene una existencia potencial; si no se inscribe no existe en el Ordenamiento (y, naturalmente, sólo en el Ordenamiento cumple su función) así que, para que quede «válidamente constituida», es necesario inscribir el «documento en que se constituya» [o, mejor, en que se constituyó] en el Registro de la Propiedad.

Por todos estos datos, nos inclinamos a pensar que la inscripción de la hipoteca es necesaria para su validez (y, por tanto, en este sentido «constitutiva»), y que así debe ser, para que la hipoteca despliegue sus efectos en el conjunto del Ordenamiento. Alabamos, por tanto, el contenido de la reforma y criticamos la falta de técnica legislativa con que dicha reforma se llevó a cabo y que originó en esta materia - parafraseando a Savigny — «un fárrago inmenso de disposiciones contradictorias». Esto es, en nuestra opinión lo que obliga a los autores a elaborar extrañas construcciones en torno a ese tema, las cuales - insistimos - se hubieran evitado si la redacción de los artículos hubiera sido coherente ${ }^{52}$.

52 Por último, en cuanto a la jurisprudencia, la práctica totalidad de las sentencias entienden que la inscripción tiene carácter constitutivo; sólo en determinados supuestos se han querido interpretar algunas sentencias en sentido contrario, pero entendemos que tales interpretaciones no son del todo posibles. Este sería el caso, por ejemplo, de las sentencias de 13 de julio de 1984 y de 31 de octubre de 1986 (vid, GORDILLO CAÑAS, en su artículo «Excerpta en tema de constitución de hipoteca voluntaria», op. cit., pp. 450-456).

Últimamente, el carácter constituvo de la inscripción hipotecaria aparece incuestionado y, a título de ejemplo, se pueden citar sentencias como la de 29 de junio de 1989 , que establece que «la hipoteca es un derecho de constitución registral que exige que el título correspondiente se haya inscrito en el Registro de la Propiedad». También la sentencia de 4 de julio de 1989 se pronuncia en el mismo sentido: «(...) siendo este caso el único que en nuestro sistema la inscripción tiene carácter constitutivo, lo cual obedece a la naturaleza de derecho formal de la hipoteca, que indudablemente es un derecho de constitución registral, y el valor constitutivo de la inscripción de hipoteca ha sido constantemente reconocido en nuestra jurisprudencia». 


\section{BIBLIOGRAFÍA}

AMORÓS GUARDIOLA, M. (1991), La publicidad registral de los préstamos hipotecarios. La transmisión de la finca hipotecada, en «Hipotecas y Seguridad Jurídica», Madrid.

BALLARÍN HERNÁNDEZ, R. (1980), La hipoteca. (Génesis de su estructura y función)., Madrid.

CÁMARA (1949), «Notas críticas sobre la naturaleza jurídica de la hipoteca como derecho real» en Revista de Derecho Privado, pp. 377-422.

CANALS BRAGE, F. (1988), «El valor de la inscripción en la hipoteca», en Centenario de la Ley de Bases del Código Civil, Madrid.

CARNELUTTI, «Natura giuridica dell'ipoteca» en Rivista di Diritto Processuale Civile, 1939, pp. 3-21.

CARRERAS (1952), El embargo de bienes, Barcelona.

CASTAN TOBEÑAS, J. (1978), Derecho Civil Español Común y Foral, T.II., vol. II, $12^{a}$ edic., Madrid.

CHICO Y ORTIZ, J.M (1989), Estudios sobre Derecho Hipotecario, T.I, Madrid. FENECH, «recepción de la hipoteca en el Derecho Procesal», en Revista de Derecho Procesal, 1952, año VIII, ${ }^{\circ}$ 4, pp. 377-422.

GARCÍA GARCÍA, J.M. (1991), «Comentario del Código Civil», Madrid.

GIORGIANI, «Diritti reali» en «Novisimo Digesto Italiano», V, p. 749 y ss.

GORDILLO CAÑAS, A. (1992), «Excerpta en tema de constitución de hipoteca voluntaria», en «Estudios de Derecho Civil en homenaje al Profesor Dr. José Luis Lacruz Berdejo», vol. I, Barcelona.

HERMIDA LINARES, M. (1949), «¿Es constitutiva la inscripción en el derecho real de hipoteca?», R.C.D.I..

IGLESIAS REDONDO, J. (1986), «Repertorio bilingüe de definiciones, reglas y máximas jurídicas romanas», Madrid.

LALAGUNA, E. (1985-1986), «Los créditos hipotecarios», en Revista de Derecho Notarial julio-diciembre 1974, pp. 109-205.

- (1973), «Los modos de adquirir la propiedad y los contratos de finalidad traslativa en el Derecho Español», en R.D.P.

NÚÑ̃Z LAGOS (1949), «El Registro de la Propiedad Español», R.C.D.I.

— «Realidad y Registros», R.C.D.I., 1945.

RAMOS FOLQUES (1949), «El principio legitimador y la hipoteca», R.C.D.I., $\mathrm{n}^{\circ} 252$.

— «La inscripción y la hipoteca hasta el Código Civil», R.C.D.I., $\mathrm{n}^{\circ} 249,1949$.

— «a hipoteca y la inscripción después del C.C.», R.C.D.I., n 250, 1949.

ROCA-SASTRE, R. (1979), «Derecho Hipotecario», $7^{\text {a }}$ edic., Barcelona (con ROCA-SASTRE MUNCUNILL).

SANZ FERNÁNDEZ (1947), «Instituciones de Derecho Hipotecario», T.I., Madrid. VALLET DE GOYTISOLO, J. (1973), Panorama del Derecho Civil, Barcelona. 